\title{
ATRIAL SEPTAL DEFECT IN CHILDREN
}

\author{
BY \\ JOAN WAGNER * AND GERALD R. GRAHAM \\ From The Congenital Heart Unit, The Hospital for Sick Children, London
}

Received February 1, 1956

This paper has a two-fold purpose: first, to present the signs and symptoms of atrial septal defect and thus outline the findings that help in making the clinical diagnosis, and secondly, to show that correct and early diagnosis is important, because this anomaly gives rise to serious, although frequently obscured, symptoms and disabilities more often than has been generally realized.

Clinically, atrial septal defect may be defined as a developmental anomaly of the atrial septum that permits a shunt of blood between the two atria. Over 300 cases of atrial septal defect have been recorded in the period 1765-1954. The first mention of a case was probably in a report by Morgagni (1765). This was followed by several reports during the nineteenth century (Corvisart, 1811; Louis, 1826; Ecker, 1839; Mayne, 1848; Peacock, 1860; Martineau, 1865; Rokitansky, 1875). When, in 1934, Roesler collected all the cases (as he thought) previously described, adding one of his own, a total of 62 had been reached. Since then the reporting of such cases has avalanched. Thus, in 1940, Tinney reviewed 24 cases from 1934-1938, Bedford et al. 53 in 1941, Cosby and Griffith 35 in 1949, and at least 200 other examples have been put on record.

The clinical diagnosis of this condition had not been well established until recently, and even now many features are disputed. With the introduction of special techniques of investigation, notably cardiac catheterization and angiocardiography, the diagnosis in life is more firmly established than before. At the same time, correlation of these investigations with the clinical findings has provided an objective check on the clinical diagnostic criteria. With the advance in cardiac surgery, which has led to several techniques for atrial septal closure, precision in diagnosis has become essential. Satisfactory clinical criteria are necessary to select cases for additional studies, such as cardiac catheterization. With these problems in mind we have reviewed the clinical profiles of 133 children with atrial septal defect.

\section{MATERIAL AND MethodS}

Out of the current list of about 1500 patients who are regularly followed in the congenital heart clinic of this hospital, 133 were found to have an atrial septal defect without other congenital cardiac anomalies. The majority of these patients had originally been referred to this clinic because of murmurs heard on routine examination. In about one-fourth of the cases the diagnosis has been confirmed by cardiac catheterization.

All patients had clinical investigations consisting of history and physical examination. Most patients had an electrocardiogram consisting of standard and unipolar limb leads V1 to V5, and in may cases V3R and V5R. Frequently, serial electrocardiograms had been taken over several years. All patients were studied fluoroscopically, including a barium swallow, and X-ray films were taken in at least two positions (postero-anterior and lateral). In addition 17 phonocardiograms and 17 jugular pulse tracings were recorded.

\footnotetext{
* Present address: Department of Medicine, University of Witwatersrand, Johannesburg, S.A.
} 


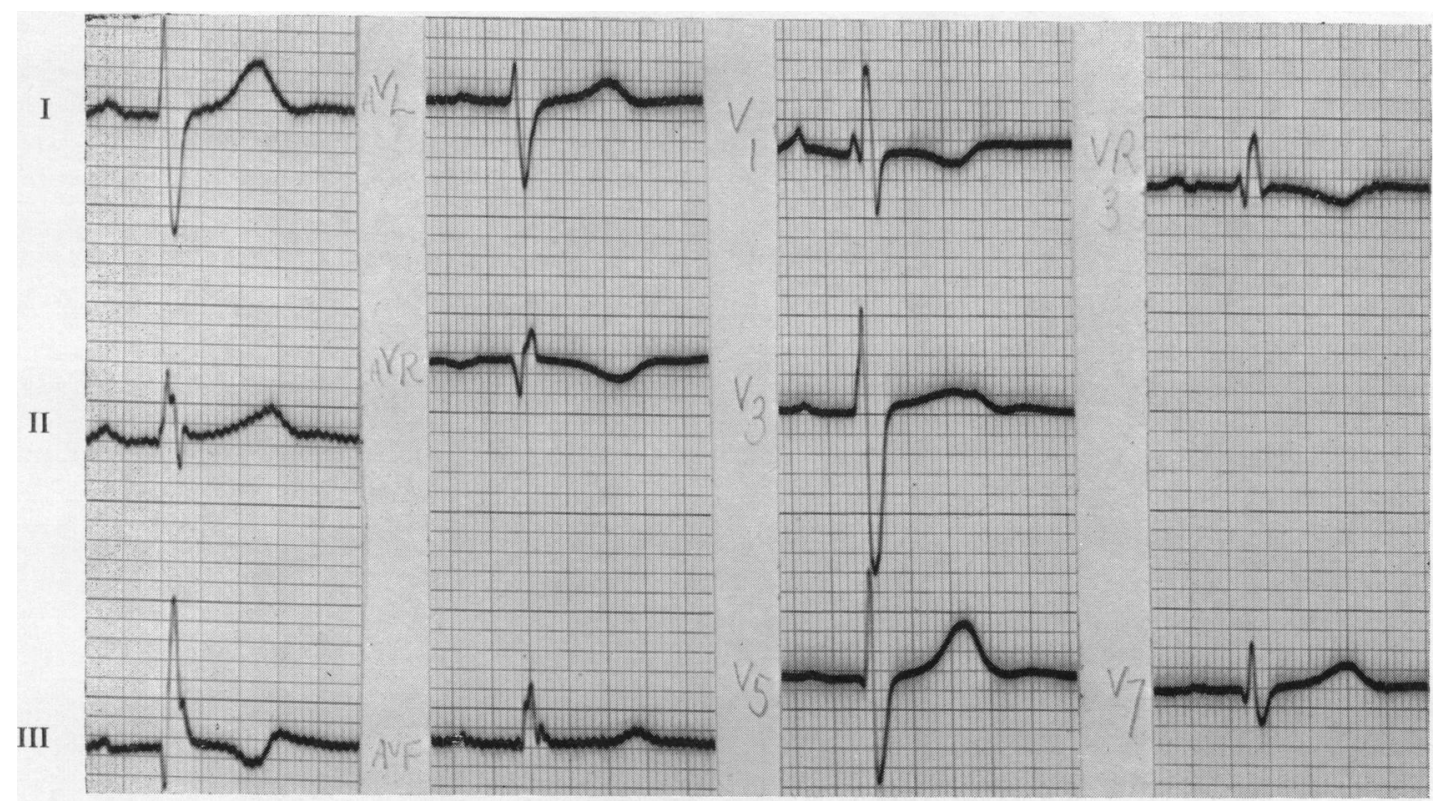

FIG. 1.-Electrocardiogram of patient, aged 10 years. Incomplete right bundle-branch block. Additional pattern of right ventricular hypertrophy equivocal. Cardiac catheterization proved atrial septal defect, with mild pulmonary arterial hypertension. (Standardization: $1 \mathrm{~cm} .=1 \mathrm{mv}$; time interval: $0 \cdot 1 \mathrm{sec}$. between heavy vertical lines.) V3R and V7 are shown on the right.

All cases in which the features were not sufficiently well defined to make the diagnosis with certainty have been omitted. Our follow-up system has often allowed us to arrive at the correct diagnosis in cases where early in the course of the disease the diagnosis was in doubt. The group can be considered a representative sample of children with this anomaly. The incidence of this defect among our patients with congenital heart disease is similar to percentages in large autopsy series (Abbott, 1936; McGinn and White, 1933; Gibson and Clifton, 1938; Ingham, 1938).

\section{RESULTS}

History. None of the mothers had had rubella or other significant illnesses during pregnancy. Labour and delivery presented no abnormal features and there was no correlation with sibling order. The neonatal period was normal in all except one infant who died aged two months. No gross abnormalities of intellectual development were observed, but neither qualitative nor quantitative tests were performed.

For the purpose of presenting the symptoms, the cases are divided into two groups according to heart size, to test whether there was a significant difference in symptoms related to this datum. The symptoms are further subdivided into those, if any, with which the child presented and those appearing subsequently.

The two outstanding symptoms were breathlessness (in 65 patients) and frequent chest infections (in 70). It should be noted that in three-quarters of the patients with normal or only slightly enlarged hearts and in half of those with much enlargement, symptoms had been insufficient for the parents to seek medical advice, the murmur having been heard on routine medical examination. However, subsequent questioning revealed that actually only one-fifth of the patients had been entirely free of symptoms, and that almost all of these had hearts of normal size.

Cyanosis at some stage, usually only temporary, was said to have been seen by the parents of one-third of the patients. 
When the symptoms of breathlessness, lassitude, and cyanosis (parental observation) were related to the patient's age when they were first observed, no great difference was found between the cases with normal or slightly enlarged hearts and those with large hearts. Similarly, when the whole group was divided into three according to age at onset of symptoms (under 1 year; 1-5 years; 5-10 years), no difference was found between patients with normal (or slightly enlarged) and those with large hearts.

Rather surprisingly, a lack of correlation between age at the time of onset of first symptoms on one hand and heart size on the other was also shown by a similar number of cases falling into each of the three age groupings.

Signs. A tumultuous apex beat and evidence of right ventricular enlargement by percussion and palpation were often present, but criteria are not standardized enough to allow tabulation.

The following were the physical signs found to be most frequent and most reliable in making the diagnosis.

(1) Enlargement of the heart involving mainly the right side (found clinically in over one-third of the series);

(2) a loud and (often widely) split pulmonary second sound (all cases);

(3) a systolic murmur at the pulmonary area (grade II in 75 per cent; grade III or IV in 22 per cent of cases), sometimes accompanied by a palpable thrill in this area (26\%); and

(4) an apical diastolic murmur (30\%).

Sex incidence was equal. The small size of the children was an outstanding feature of the group, especially as regards weight (62 per cent were of normal height, but only 25 per cent of normal weight).

In many cases the jugular pulse (Reinhold, 1955) showed very tall $v$ waves, presumably the result of increased right atrial inflow, but normal $a$ and $c$ waves. Prominent $a$ waves, on the other hand, were found only when pulmonary hypertension co-existed, but were not diagnostic of atrial septal defect per se. The incidence of these findings is not recorded, because they were not looked for in all cases.

Associated Diseases and Anomalies. Other cardiac anomalies are excluded from this series. Rheumatic fever, with or without heart disease, occurred in only one case. Subacute bacterial endocarditis was never diagnosed. Physical abnormalities, other than of growth, were uncommon. Two cases showed mongolism. In twenty cases there were physical abnormalities such as pigeon chest and Harrison's sulcus, but the anomalies were severe, in two patients only, in one idiot and in one with an Ellis van Creeveld syndrome.

Electrocardiogram. Of the 13 patients with standard leads almost half showed abnormalities. On the basis of the remainder in whom additional unipolar limb and præcordial leads were also taken, it is likely that abnormalities were missed in these. In an analysis of the findings, it has been thought fairest to consider this group of 120 patients separately (Group B). Ninety per cent of the multi-lead electrocardiograms were abnormal, over 85 per cent of them showing right ventricular hypertrophy, right bundle-branch block (complete or incomplete), or both. Slightly more than half had right ventricular hypertrophy, frequently associated with some form of right bundlebranch block, while two-thirds of this group showed complete or incomplete right bundle-branch block. P wave abnormalities were infrequent and did not correlate well either with right atrial size or pressure where this was obtained during cardiac catheterization.

Fluoroscopic and $X$-ray Examination. The typical radiological changes were right-sided cardiac enlargement, prominent right ventricular outflow tract, a pulmonary artery with active pulsation, and increased pulmonary vascularity with dilated main pulmonary artery branches (Fig. 2). Right atrial enlargement was not specifically diagnosed by us, because its radiological criteria are so illdefined and controversial. Barium swallow showed typically a small aortic, a long pulmonary, and a normal cardiac impression. The films were at times useful as a permanent record and in judging pulmonary vascular changes. Fluoroscopy was by far the most informative examination. 
A

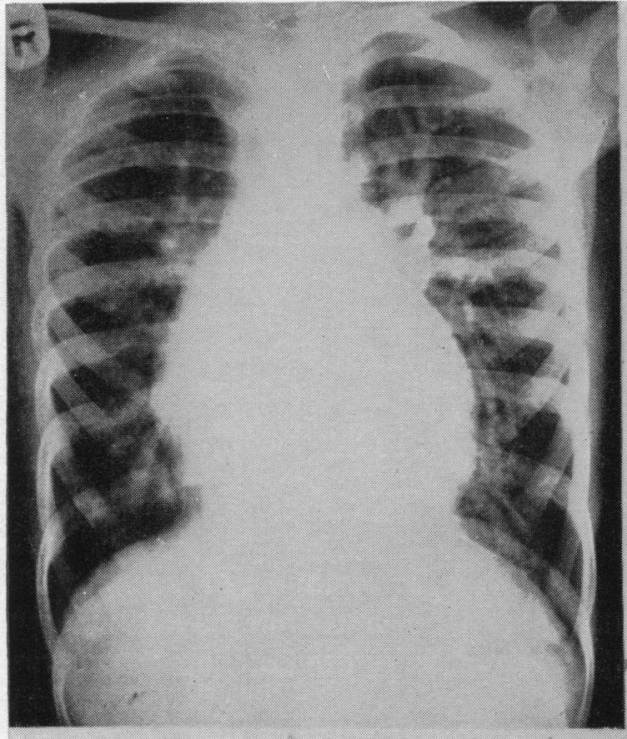

\footnotetext{
2

C
}

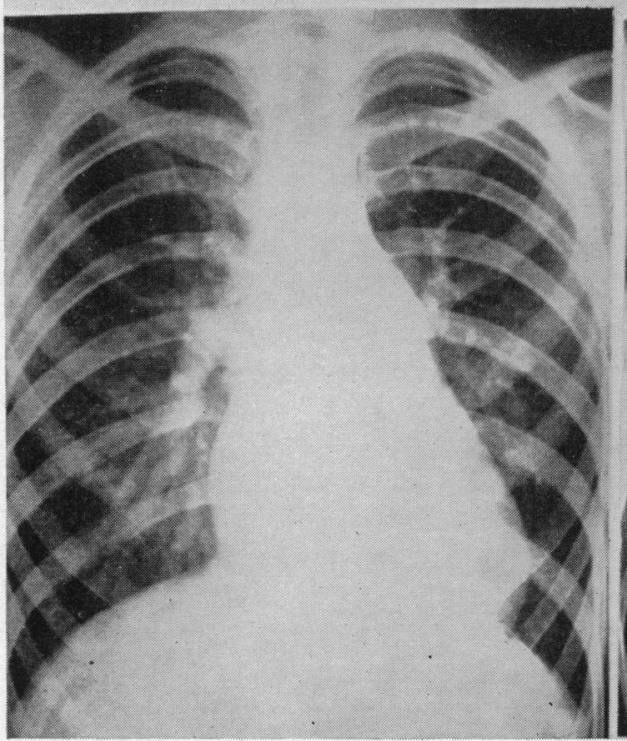

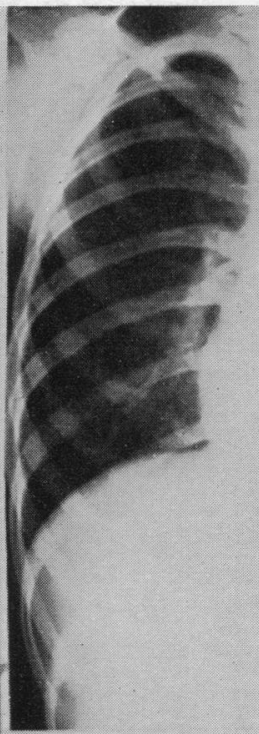

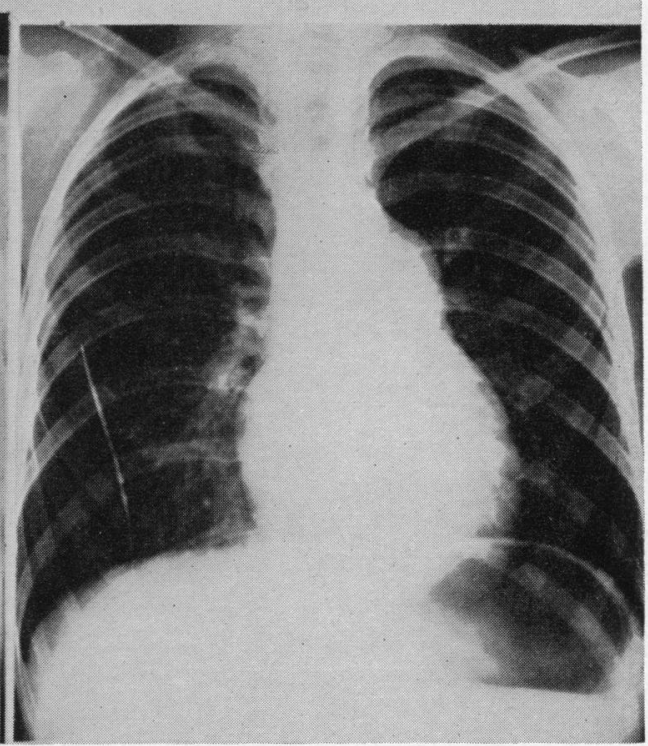

FIG. 2.-X-rays of chest in atrial septal defect. (A) and (B). Patiends with normal pulmonary artery pressures. (C) and (D). Patients with severe pulmonary artery hypertension. (For explanation see text.)

Deaths. Six patients died, aged two months, four months, twenty months, three, four, and five years, respectively. Congestive heart failure was the cause of death in four, bronchopneumonia in one, and the sixth died after an attempt at surgical closure. The average age of death in the Roesler (1934) series was 36, in Welch and Kinney's series 33 (1940) and in Burnett and White's 39 years (1945). 
The Symptoms. Breathlessness and frequent chest infections were the two outstanding symptoms. It would be tempting to relate both to the increased pulmonary flow, but other congenital cardiac defects with left-to-right shunts, such as patent ductus, ventricular septal defect or Eisenmenger's complex, do not lead to these complaints to the same extent. Data are, however, too sparse to correlate the amount of total pulmonary flow with symptoms in such anomalies.

Our data show that very few of the children remained without symptoms while under observation, although many of them had the defect diagnosed on routine medical examination. Inadequate gain in weight was the most striking clinical finding. While comparative data are meagre, it is our experience that no other acyanotic congenital heart disease shows this feature either as frequently or as severely. On the whole, these findings are comparable with those of other authors. The frequency of symptoms is generally stressed (Barber et al., 1950; Bedford et al., 1941; Burnett and White, 1945; Cosby and Griffith, 1949; Roesler, 1934).

The Signs. The physical signs that we found agree with those of the more recent reports. For many years following the first clinical description of atrial septal defect, the typical murmur was thought to be " presystolic and synchronous with atrial systole," a view held by Tilbury Fox in 1859 and still supported by Carpenter in 1909. It is by now agreed, however, that the typical and usual murmur is systolic. Atrial septal defects without murmurs have been described (Peacock, 1860; Lumsden, 1946) but in the absence of a murmur one would hesitate to make the diagnosis and rather classify the condition as anomalous drainage of the pulmonary veins which may give signs and symptoms of atrial septal defect in the absence of a murmur.

The cause and origin of the systolic murmur are unanswered problems. It may be due to the interatrial flow of blood, which is maximal during ventricular systole. Usually the murmur is high along the left sternal border and of rather limited transmission, but cardiac size and position and extracardiac factors may influence the loudness and location of any murmur to make these details variable. Because interatrial pressure gradients are small, flow through the defect, although it may be large, does not cause the type of turbulence and vibration that, in interventricular septal defects, give rise to a loud and coarse murmur. A thrill is, therefore, felt only very rarely from this cause alone.

In almost one-third of our cases an apical diastolic murmur was heard. Other authors have reported a similar incidence. The production of this murmur and its possible relation to Lutembacher's syndrome have caused considerable controversy. Both autopsy findings and observation at the time of surgical closure have shown that in many cases, particularly if the shunt is large, the left ventricle, including the mitral valvular ring, failed to develop to their normal proportions. An apical diastolic murmur may, thus, be due to turbulence created at a hypoplastic, but otherwise normal, mitral valve from which, due to its small size, a considerable portion of left atrial inflow is shunted across the defect as this route offers less resistance to the flow. Another suggested cause is the large increase in flow through the tricuspid valve, the murmur being due to "relative" tricuspid stenosis. Pulmonary valvular regurgitation with an unusual transmission of its murmur has been given as another explanation. Finally, a late diastolic or presystolic murmur may be due to the brief but rapid shunt during atrial contraction when the pressure in the left atrium may exceed that in the right more than during other parts of the cardiac cycle.

The nature of the diastolic murmur is a matter for speculation. Other conditions may cause this murmur (e.g. patent ductus arteriosus, ventricular septal defect). It is important to know whether mitral stenosis co-exists. This syndrome has become associated with the name of Lutembacher (1916 and 1936). The frequency of this combination has never been satisfactorily settled. In several large unselected autopsy series the incidence ranged from 0.01 per cent to 0.03 per cent (Gelfman and Levine, 1942; McGinn and White, 1933; Nadas and Alimurung, 1952). Of 100 cases of acyanotic congenital heart disease, which were later examined post mortem, an apical diastolic murmur had been heard in 19, of whom 6 had an atrial septal defect; mitral stenosis was 
absent in all (Nadas and Alimurung, 1952). Cosby and Griffith (1949) likewise found no case of mitral stenosis in 19 cases of atrial septal defect.

Our own observations support the view that Lutembacher's syndrome is exceedingly rare, and that apical diastolic murmurs frequently occur in uncomplicated atrial septal defect.

In addition to the murmurs, the character of the second sound heard in the pulmonary area is the most important physical sign. It was significantly loud and split in all our cases. In atrial septal defect the split is usually conspicuously wide or even palpable and can be attributed either to delay in emptying of the overfilled right ventricle, to bundle-branch block, or both. The pulmonary element is loud, either due to the proximity of the dilated pulmonary artery to the chest wall, pulmonary hypertension or the increased systolic filling of the main pulmonary vessels. However, the "split" may become less marked and even disappear with the development of pulmonary hypertension.

Cyanosis was occasionally observed in our patients. But in only ten had it become permanent. Since the occurrence of cyanosis in atrial septal defect uncomplicated by other congenital anomalies depends on the rise of right atrial pressure until it exceeds that of the left, the presence of a right-toleft shunt presupposes the existence of pulmonary and right ventricular hypertension resulting from increased pulmonary vascular resistance. The cause or causes of the increased resistance are still under dispute, and consequently there is no consensus whether such changes are wholly or partially reversible. But it is possible that the reversal of the interatrial shunt is a danger signal that circulatory changes may have progressed beyond the point where much benefit can be expected from surgical closure.

Subacute bacterial endocarditis, not found in any of our own cases, is an extremely rare complication judging by previously recorded series. Only six such cases have been found (Abbott, 1938; Bedford et al. 1941; Griffith, 1906), two of whom had the vegetations on the septal defect (Tinney and Barnes, 1947; Jacobius and Moore, 1938).

Only one of our patients contracted rheumatic fever. Of 64 cases described by Roesler, 41 had rheumatic fever, of whom 61 per cent had mitral valvular lesions. But actually only 6 were of the button-hole type, the rest varying from thickening of the valves to mitral insufficiency. These figures, taken together with those of Lutembacher's syndrome quoted previously, make one rather sceptical of Burnett and White's dictum (1945) that mitral valvular disease should be suspected rather than rejected in every case of atrial septal defect.

Associated physical abnormalities, other than smallness of weight and shape of chest, are rare in our series, and have not been commonly reported by others.

The Electrocardiogram. Some type of right bundle-branch block was found in 60 per cent of the electrocardiograms. Right ventricular hypertrophy was present in 67 cases, associated with complete or incomplete right bundle-branch block in 38. In a few instances this combination could be seen to have developed from incomplete right bundle-branch block in two to three years. It must be remembered that an identical pattern can be found in pulmonary stenosis and in other conditions (Barber et al., 1950). The cause of the block is not certain, but it is probably associated with dilatation and hypertrophy of the right ventricle rather than with a local lesion in the interventricular septum.

Correlating the electrocardiogram with pulmonary artery pressures, where these were known, there was always right ventricular hypertrophy in the presence of pulmonary hypertension, but right ventricular hypertrophy also occurred where pressure was normal. It therefore seems that increased "flow" hypertrophy is indistinguishable from " pressure" hypertrophy electrocardiographically. The only normal electrocardiogram among those patients studied by cardiac catheterization was in a case with normal right ventricular pressure and a small interatrial shunt.

$X$-ray Examination. This we found a crucial part of the clinical evaluation for several reasons. First, it aids significantly in differential diagnosis. Secondly, the degree of pleonæmia of the lungfields provides a measure of the size of the left-to-right interatrial shunt. Thirdly, the results 
TABLE I

Symptoms of Atrial Septal Defect classified according to Heart Size

\begin{tabular}{|c|c|c|c|c|c|c|}
\hline & & & & & $\begin{array}{l}82 \text { patients with normal or } \\
\text { slightly enlarged hearts }\end{array}$ & 51 patients with large hearts \\
\hline \multicolumn{5}{|l|}{$\begin{array}{l}\text { Presenting symptoms } \\
\text { A. Incidentally found murmur }\end{array}$} & 60 & 27 \\
\hline \multicolumn{5}{|c|}{ 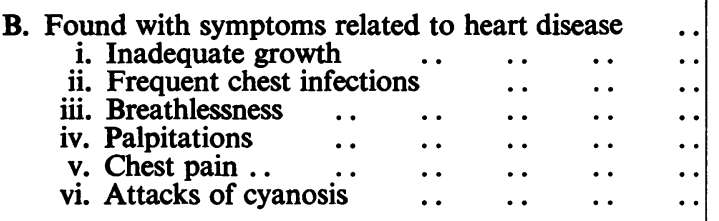 } & $\begin{array}{r}23 \\
11 \\
7 \\
2 \\
1 \\
1 \\
0\end{array}$ & $\begin{array}{r}24 \\
2 \\
11 \\
3 \\
3 \\
0 \\
1\end{array}$ \\
\hline 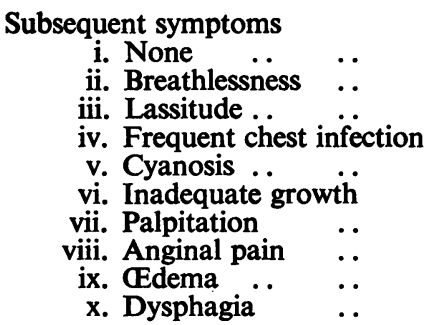 & 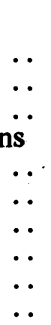 & 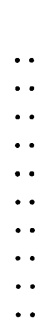 & 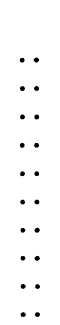 & $\ddot{.}$ & $\begin{array}{r}22 \\
31 \\
16 \\
30 \\
14 \\
12 \\
2 \\
2 \\
0 \\
0\end{array}$ & $\begin{array}{r}5 \\
29 \\
12 \\
22 \\
18 \\
4 \\
3 \\
0 \\
1 \\
1\end{array}$ \\
\hline
\end{tabular}

TABLE II

Electrocardiographic Findings in 133 Cases of Atrial Septal Defect

A. Electrocardiograms with 3 standard limb leads only (13 cases)

Normal

Abnormal

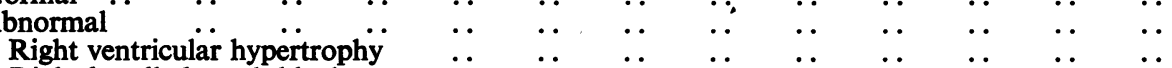

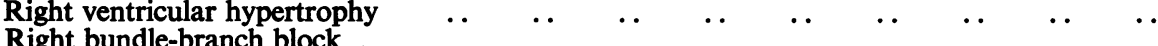

$\begin{array}{lllllllllll}\text { Dextrocardia } & . . & . . & . & . . & . & . . & . & . . & . & . \\ \end{array}$

$\begin{array}{cc} & \text { Nos. } \\ \ldots & 7 \\ \ldots & 6 \\ \ldots & 3 \\ \ldots & 2 \\ \ldots & 1\end{array}$

B. Electrocardiograms with at least 3 standard limb and 3 unipolar precordial (V) leads (120 cases)

\section{Normal}

Abnormal

(a) Non-specific

(b) Right ventricular hypertrophy

Uncomplicated

With complete right bundie-branch block

With incomplete right bundle-branch block

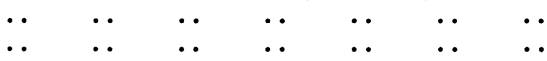

12

$\because$

(c) Right bundle-branch block

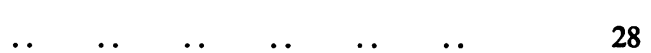

Total

$\overline{64}$

$\begin{array}{lllllllll}\text { Uncomplicated } & \ldots & \ldots & \ldots & & & & & \\ \text { With right ventricular hypertrophy } & \ldots & \ldots & \ldots & . & \ldots & . & \ldots & \ldots\end{array}$

Total $\frac{11}{25}$

(d) Incomplete right bundle-branch block

Uncomplicated

With right ventricular hypertrophy

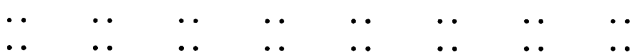

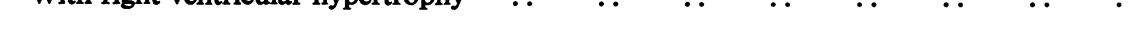

(e) Abnormal P waves (associated with other electrocardiographic abnormalities) $\ldots \ldots$ Total 5

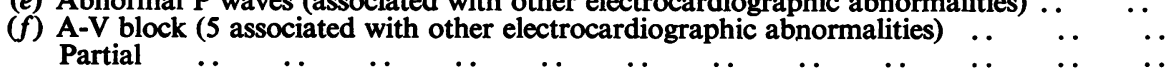
Complete :. 
of fluoroscopy and the inspection of the X-ray films give one a hint about the presence of pulmonary hypertension. The combination of right ventricular hypertrophy, prominent pulmonary conus, large pulmonary arteries, but an abrupt ending of the root branches into small, tortuous vessels with a discrepancy between the size of the central arteries and the peripheral vascularity have correlated well with the presence of pulmonary hypertension when this could be checked by cardiac catheterization. Because the presence or development of pulmonary hypertension is of importance in selecting patients for further study careful attention should be paid to this radiological appearance, although our own observations do not show how far its presence or absence is diagnostic. A striking, and unexpected, finding in this series was the slight correlation between heart size and symptoms (Tables I and II), so that the latter cannot be used as a reliable index of the disturbed

TABLE III

Results of X-ray Examinations in 133 Cases of Atrial Septal Defect

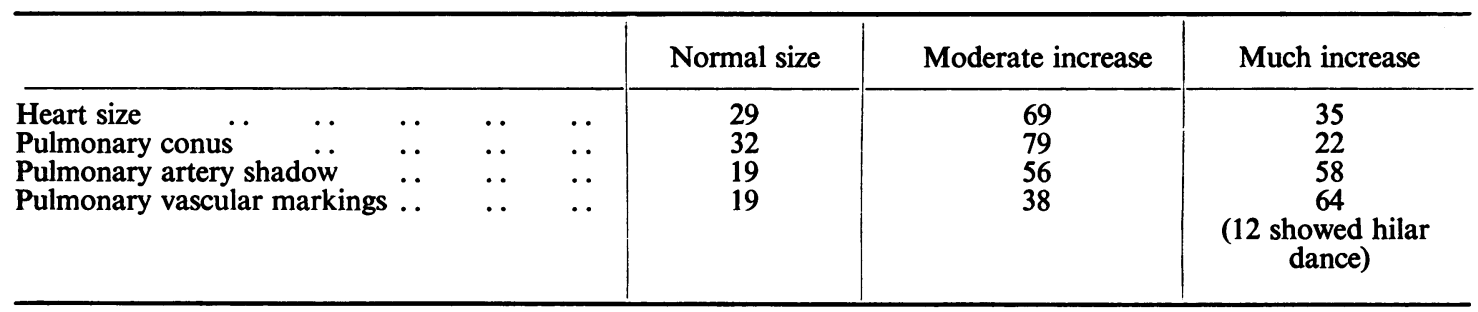

Barium swallow showed the " typical" change of small aortic-long pulmonary-normal cardiac shadow in 67 cases.

circulatory dynamics. In fact, symptoms may te utterly misleading and it is often left to radiological examination to provide the first objective clue to the harmful consequences of an interatrial shunt (Plates A-D, Fig. 2).

\section{SUMMARY}

This paper reviews the history, physical examination, X-ray findings, and electrocardiograms of 133 children with atrial septal defect. All of the patients have been followed over a period of several years and many have been studied by cardiac catheterization.

From this series a composite profile of the child with atrial septal defect may be constructed. This anomaly often gives rise to serious symptoms and disabilities, which commonly appear in childhood. Growth is usually slightly retarded with a striking weight deficit. Breathlessness is common and chest infections frequently occur.

The heart is usually slightly enlarged. The pulmonary second sound is loud and split, the second component being accentuated. A systolic murmur is easily heard, loudest in the second or third left interspace. A soft apical diastolic murmur is common. The electrocardiogram often shows incomplete or complete right bundle-branch block, right ventricular hypertrophy, or both. The X-ray findings are of right ventricular enlargement, prominent pulmonary conus, large pulsatile pulmonary arteries and major branches, and increased vascularity of the lung fields. The presence of pulmonary hypertension and the size of the interatrial shunt can often be suspected from the radiological appearance.

This group shows a lack of correlation between presenting and subsequent symptoms on one hand and objective evidence of cardiac disease on the other.

We would like to thank Dr. R. E. Bonham-Carter for permission to publish facts about these patients, all of whom were under his care, and for his helpful criticism and advice in the preparation of this paper. We thank, too, Dr. J. Wells who examined the patients fluoroscopically, Dr. J. Reinhold who examined many of the electrocardiograms, and Mr. Derek Martin who prepared the photographs of the X-ray films. 


\section{REFERENCES}

Abbott, M. (1936). Atlas of Congenital Cardiac Disease. New York.

Barber, J. M., Magidson, O., and Wood, P. (1950). Brit. Heart J., 12, 277.

Bedford, D. E., Papp, C., and Parkinson, J. (1941). Brit. Heart J., 3, 37.

Brannon, E. S., Weens, H. S., and Warren, J. V. (1945). Amer. J. med. Sci., 210, 480.

Burnett, J. B., and White, P. D. (1945). Amer. J. med. Sci., 209, 355.

Carlenter, G. (1909). Proc. roy. Soc. Med. (Section for the Study of Disease in Children), 2, 36.

Corvisart, J. N. (1848). Essai sur les Maladies et les Lesions Organiques du Caur et des Gros Vaisseaux. Paris. P. 279.

Cosby, R. S., and Griffith, G. C. (1949). Amer. Heart J., 38, 80.

et al. (1953). Amer. J. Med., 14, 4.

Courter, S. R., Felson, B., and McGuire, J. (1948). Amer. J. med. Sci., 216, 501.

Dry, T. J. (1948). Med. Clin. N. Amer., 32, 895.

Ecker, A. (1839). Beschreibungen einiger Falle von anomaler Communication der Herzvorhöfe, etc. Freiburg.

Erlanger, H., and Levine, S. A. (1943). Amer. Heart J., 26, 520.

Fox, T. (1859). Med. Times \& Gaz., 19, 209-210 and 254.

Gelfman, R., and Levine, S. A. (1942). Amer. J. med. Sci., 204, 324.

Gibson, S., and Clifton, W. M. (1938). Amer. J. Dis. Children, 55, 761.

-, and Roos, A. (1935). Amer. J. Dis. Children, 50, 1465.

Griffith, T. W. (1903). Med. Chron., 385. (1906). Lancet, 1, 973.

Harp, V. V. (1949). Calif. Med., 71, 297.

Howarth, S., McMichael, J., and Sharpey-Schafer, E. P. (1947). Brit. Heart J., 9, 292.

Ingham, D. W. (1938). J. techn. Meth., 18, 131.

Jacobius, H., and Moore, R. A. (1938). J. techn. Meth., 18, 133.

Johnson, G. (1878). Brit. med. J., 1,333.

Keith, J. D., and Forsyth, C. C. (1951). J. Pediat., 38, 172.

Louis, P. C. A. (1826). Memoires, ou recherches anatomico-pathologiques, etc. Paris, p. 302.

Luisada, A. A., and Montes, L. P. (1950). Ann. intern. Med., 33, 56.

Lumsden, C. E. (1946). Brit. med. J., 2, 734.

Lutembacher, R. (1916). Arch. Mal. Caur., 9, 237.

(1936). Arch. Mal. Cour., 29, 229.

McGinn, L., and White, P. (1933). Amer. Heart J., 9, 1.

Martineau, -. (1865). Bull. Soc. anat. (Paris), 10, 310.

Massee, J. C. (1947). Amer. J. med. Sci., 214, 248.

Matthews, M. B. (1949). St. Thom. Hosp. Rep., 5, 10.

Mayne, R. (1848). Dublin J. med. Sci., 5, 46.

Morgagni, J. B. (1765). De Sedibus et Causis Morberum per Anatomen Indagatis. Padua. Epist. Anat. Med., XVII. Art. 12.

Nadas, A. S., and Alimurung, M. M. (1952). Amer. Heart J., 43, 691.

Peacock, T. B. (1860). Trans. path. Soc. London, 11, 68.

Reinhold, J. (1955). In press.

Roesler, H. (1934). Arch. intern. Med., 54, 339.

Rokitansky, C. (1875). Die Defecte der Scheidewände des Herzens. Wien. Pp. 36-54.

Selzer, A., and Lewis, A. E. (1949). Amer. J. med. Sci., 218, 516.

Shah, V. V. (1949). Indian Physician, 8, 81.

Susman, M. L., Grishman, A., and Steinberg, M. F. (1943). Amer. J. Dis. Children, 65, 922.

Taussig, H. B., Harvey, A. McG., and Follis, R. H. (1938). Bull. Johns Hopk. Hosp., 63, 61.

Tinney, W. S. (1940). Arch. intern. Med., 66, 807.

and Barnes, A. R. (1942). Minn. Med., 25, 637.

Welch, K. J., and Kinney, T. D. (1940). Amer. J. Path., 24, 729. 